\title{
The effects of metformin and alendronate in attenuating bone loss and improving glucose metabolism in diabetes mellitus mice
}

\author{
Qiyun Zhou ${ }^{1,2, *}$, Zhiqiang Guan ${ }^{3, *}$, Shengfu Liu ${ }^{1, *}$, Yanjiao Xuan ${ }^{4}$, Gang Han ${ }^{2}$, Hua Chen², Xiao Jin', \\ Kun Tao' ${ }^{1}$, Zhiyuan Guan ${ }^{1}$ \\ ${ }^{1}$ Department of Orthopedics, The Shanghai Tenth People's Hospital of Tongji University, Shanghai, PR China \\ ${ }^{2}$ Department of Orthopedics, Qinghai Provincial People's Hospital, Xining, Qinghai, PR China \\ ${ }^{3}$ Department of Dermatology, The First People's Hospital of Xuzhou, Xuzhou, Jiangsu 221002, PR China \\ ${ }^{4}$ Department of Radiology, Beijing Jishuitan Hospital, Beijing 10035, PR China \\ ${ }^{5}$ Department of Rheumatology and Immunology, The First People's Hospital of Xuzhou, Xuzhou, Jiangsu 221002, \\ PR China \\ ${ }^{*}$ Equal contribution
}

Correspondence to: Xiao Jin, Kun Tao, Zhiyuan Guan; email: jinxiao202122@163.com, https://orcid.org/0000-0002-7852-

4117; doctk@163.com, https://orcid.org/0000-0002-7080-3154; gzy 2008@bjmu.edu.cn

Keywords: alendronate, metformin, diabetes osteoporosis, combined medication

Received: August 9, $2021 \quad$ Accepted: November 24, $2021 \quad$ Published: January 14, 2022

Copyright: (C 2022 Zhou et al. This is an open access article distributed under the terms of the Creative Commons Attribution License (CC BY 3.0), which permits unrestricted use, distribution, and reproduction in any medium, provided the original author and source are credited.

\section{ABSTRACT}

Background: To explore the anti-osteoporosis and anti-diabetes effects and potential underlying mechanisms of treatment with metformin and alendronate in diabetes mellitus mice.

Methods: Eight-week-old C57 BL/KS db/db and db/+ female mice were evaluated according to the following treatment group for 12 weeks: control group, diabetes mellitus group, diabetes mellitus with metformin group, diabetes mellitus with Alendronate group, diabetes mellitus with metformin plus alendronate group. Glucose level, glucose tolerance test, bone mineral density, bone microarchitecture, bone histomorphometry, serum biomarkers, and qPCR analysis.

Results: Combined metformin and alendronate can improve progression in glucose metabolism and bone metabolism, including blood glucose levels, blood glucose levels after $\mathbf{4}$ and $\mathbf{1 6}$ hours fasting, glucose tolerance test results, insulin sensitivity and reduces bone loss than the diabetes group. The use of alendronate alone can increase significantly serum glucagon-like peptide-1 levels than the diabetes group. The use of metformin alone can improve bone microstructure such as Tb.Sp and Tb.N of spine in diabetic mice.

Conclusion: The combined use of alendronate and metformin has an anti-diabetes and anti-osteoporotic effect compared with diabetic mice, but they appear to act no obvious synergistically between alendronate and metformin.

\section{INTRODUCTION}

Globally, diabetic patients have quadrupled in the past 30 years and diabetes has become the ninth major cause of death. One in eleven adults worldwide suffers from diabetes and $90 \%$ of diabetes patients suffer from type 2 diabetes [1,2]. Osteoporosis is also one of the diseases that seriously impair the health of the elderly. In the United
States, osteoporosis contributed about 1.5 million fractures each year [3, 4]. Osteoporosis and diabetes mellitus are both chronic diseases and show a clear link to morbidity and mortality [5]. Complications of diabetes were also significantly associated with fractures after falling [6-9].

Metformin, an anti-diabetic drug, can significantly improve the progression of a variety of diseases, 
including polycystic ovary syndrome, tuberculosis, cardiovascular [10], and neurological diseases [11]. The effects of metformin on bone metabolism have also been studied $[12,13]$. Existing research recognizes that Metformin played a critical role in osteoporosis by inhibiting systemic inflammation and promoting osteoclast formation [14-16]. Anti-osteoporosis drugs such as alendronate can also improve the progression of diabetes. In the clinical study, administration of 70 $\mathrm{mg}$ /week alendronate improves fasting plasma glucose, $\mathrm{HbAlc}$, and insulin indices in postmenopausal women [17]. However, anti-osteoporotic treatment does not alter the development of diabetes in the meta-analysis [18].

Because diabetes and osteoporosis are both important metabolic diseases, it is very important to know whether the combined use of anti-osteoporosis drugs and antidiabetic drugs will improve the progression of diabetes and the progression of diabetic osteoporosis. Therefore, the purpose of our study consisted of analyzing the effects of combined metformin and alendronate on diabetic-induced bone loss and possible mechanisms.

\section{MATERIALS AND METHODS}

\section{Animal experimental procedures}

Eight-week-old C57 BL/KS db/db female mice (Lepr$\mathrm{KO} / \mathrm{KO}, n=36$ ) and non-diabetic (C57BLKS-Lepr-db/+, $n=9$ ) were purchased from Beijing Vital River Laboratory Animal Technology (Beijing, China). A blood glucose level higher than $11.1 \mathrm{mmol} / \mathrm{L}$ was considered a hyperglycemic state. All experimental protocols and animal handling procedures were conducted according to the recommendations in the Guide for the Care and Use of Laboratory Animals, published by the National Institutes of Health (Publications No. 80-23, revised in 1996). This study was approved by the Experimental Animal Committee of our hospital.

After one week of adaptive feeding (mice were maintained in a standard animal facility with controlled temperature $\left(22^{\circ} \mathrm{C}\right)$ and photoperiod $(12 \mathrm{~h} \mathrm{light}$ and $12 \mathrm{~h}$ dark) and free access to freshwater and food), mice were raised in the SPF animal house after treatment. and then random grouping was carried out after the treatment, divided into five groups, such as control group (Con, C57BLKS-Lepr-db/+, $N=9$ ), diabetes mellitus group (DM, $N=9$ ), DM with metformin group receiving daily metformin at $113.75 \mathrm{mg} / \mathrm{kg}(\mathrm{DM}+\mathrm{MET}, N=9)$ [19], Alendronate group receiving daily alendronate at 0.5 $\mathrm{mg} / \mathrm{kg}$ (DM + ALE, $N=9$ ) [20], metformin plus Alendronate group receiving daily alendronate at 0.5 $\mathrm{mg} / \mathrm{kg}$ and metformin at $113.75 \mathrm{mg} / \mathrm{kg}$ (DM + MET + ALE, $N=9$ ). The Control group was treated with no metformin or alendronate at all. All drugs were administered intragastrically in normal saline solution beginning at 8 weeks of age and lasting for 12 weeks.

\section{Fasting blood glucose (FBG) and oral glucose tolerance test (GTT)}

For the fasting blood glucose, glucose tolerance assays, and insulin tolerance exam as described by Amir [21]. After 12 weeks of treatment, fasted mice $(16 \mathrm{~h}$, paper bedding) by monitoring glucose levels after a glucose bolus $(1 \mathrm{~g} / \mathrm{kg}$ of body weight (BW)) or insulin $(0.5 \mathrm{U} / \mathrm{kg}$ BW) by intraperitoneal (IP) injection. The exam of glucose was carried from fasted (4-16 h) or re-fed animals (15 min to $1 \mathrm{~h}$ ). Re-feeding was conducted by injecting a bolus of glucose $(1 \mathrm{~g} / \mathrm{kg}$ of BW) IP as mentioned above. The first drop of blood was thrown away and then the second drop of blood was detected by the glucometer (Roche Diagnostics, Mannheim, Germany). We collected the tail blood samples at $0,15,30,60$, and 120 min after glucose loading and detected the blood glucose value by the glucometer (Roche Diagnostics, Mannheim, Germany).

\section{Serum markers examination}

Serum OCN, GLP-1, CTX-1, and TRAP 5b concentrations ( $n=9$ for each group) of all mice in the current study were quantified after fasting for $8 \mathrm{~h}$ using commercial enzyme-linked immunosorbent assay (ELISA) kits (CUSABIO Biotech Co., Wuhan, China) according to the manufacturer's instructions.

\section{Radiology examination}

BMD of the whole tibiae and L4 were measured by a DXA (Faxitron ${ }^{\circledR}$ LX-60 Cabinet radiography system, US) and Micro-CT (Inveon, Siemens, Erlangen, Germany). The scanning parameters used were $70 \mathrm{kVp}$, $111 \mu \mathrm{A}$, and 1000 projections per $180^{\circ}$, resulting in a $10.5 \mu \mathrm{m}$ isotropic voxel size and a total scan time of $13.2 \mathrm{~min}$. Trabecular bone micro-architecture was assessed using the $\mu \mathrm{CT}$ Evaluation Program (Image Processing Language v. 5.0A, Scanco) [22, 23].

\section{Biomechanical examination}

The collected femurs were wrapped up using etamine soaked with normal saline, which was then stored at low temperatures. The length of the specimen was the full length of the femur. Specimens were subjected to compressive loading on a biomechanical testing machine with a loading speed of $2 \mathrm{~mm} / \mathrm{min}$ [20].

\section{Histomorphometry}

The proximal tibia was dehydrated, embedded, sliced and then the calcein double-labeling sections were 
analyzed, which included mineral apposition rate (MAR) and bone formation rate per bone surface (BFR/BS) [24].

\section{qPCR}

Tibias were cleaned of muscle and connective tissue, flash-frozen in liquid nitrogen, and stored at $-80^{\circ} \mathrm{C}$. Frozen tibias were crushed under liquid nitrogen conditions with a Bessman tissue pulverizer (Spectrum Laboratories, Rancho Dominguez, CA, USA). Total RNA was extracted using Trizol reagent (Invitrogen, Carlsbad, CA, USA). The expression levels of bone metabolism, glucose metabolism, and inflammationrelated genes, including ALP, OCN, BMP-2, Runx-2, Beclin-1, AMPK, OPG, COL1A1, Gfi1, OPN, GPR43, GPR41, GCG, RANKL, PC1/3, which has been upload in Supplementary Table 1 . The relative change in gene expression was analyzed by the $2^{-\Delta \Delta \mathrm{CT}}$ method. The mRNA of ALP, OCN, BMP-2, Runx-2, Beclin-1, AMPK, OPG, COL1A1, Gfi1, OPN, RANKL, is calculated with the DM group as the baseline, and the mRNA of GPR43, GPR41, GCG, PC1/3 is calculated with the control group as the baseline.

\section{Statistical analysis}

All measurements are presented as the mean \pm standard deviation (SD) and a $P$-value of $\leq 0.05$ was considered statistically significant. Bodyweight of the time-course study was analyzed by two-way repeated-measures analysis of variance (ANOVA). Data were analyzed for intervention and time main effects. The data were analyzed using GraphPad Prism 8.02 (La Jolla California, USA) and one-way ANOVA followed by Tukey's multiple.

\section{Ethical approval}

All procedures performed in studies involving animal were in accordance with the ethical standards of the institutional (LA221221).

\section{RESULTS}

The effect of metformin and alendronate on body weight and food intake

We analyzed the changes in the body weight and found that diabetic mice increased body weight significantly. After treatment with metformin and alendronate alone, the bodyweight significantly reduced compared with the diabetic group and the combined treatment also decreased significantly in the bodyweight than treatment with metformin and alendronate alone (Figure 1A, 1B). The food intake has also shown some kind of pattern with a change of body weight (Figure 1C, 1D).

\section{The effect of metformin and alendronate on glucose metabolism}

Because metformin and alendronate also have significant effects on glucose metabolism, we assessed the effects of using alone or in combination alendronate and metformin treatment on glucose metabolism. We found that the use of metformin alone and the combined use of metformin and alendronate significantly improved blood glucose levels, but the use of alendronate alone did not improve blood glucose significantly (Figure 1E, 1F). The experiment of serum glucose test after 4 hour fasting and 16-hour fasting, GTT test and insulin levels and insulin sensitivity can only be improved in both the use of metformin alone and the combined use of metformin and alendronate (Figure 2A-2C) but the use of alendronate has a weaker effect on glucose metabolism (Figure 2D, 2E).

\section{The effect of metformin and alendronate on bone microstructure}

We found that combined utilization of alendronate and metformin can improve the BV/TV, Tb.N, Tb.Sp of the spine and BV/TV, Tb.Th and Tb.N of the tibia than diabetes group. besides, the use of alendronate alone can be increased significantly in BV/TV of tibia and decreased significantly in Tb.Sp of spine. The use of metformin alone can improve Tb.N and Tb.Sp of spine than diabetes mice (Figure 3A-3H).

DXA analysis found that diabetes can decrease significantly in bone mass density (BMD) of the spine and tibia. The use of alendronate alone and the combined use of alendronate and metformin can significantly improve bone loss, but for metformin, it does not significantly improve $\mathrm{BMD}$ of the spine and tibia (Figure 4, Figure 5A, 5B).

For the results of tibial cortical bone, it was found that the use of alendronate alone and the combined use of alendronate and metformin can improve the thickness of cortical bone, but there is no significant effect on the area of cortical bone (Ct.Ar) (Figure 5C, 5D).

\section{The effect of metformin and alendronate on pathology and biomechanics}

We found that the combination of alendronate and metformin can increase the result of MAR and BFR/BS than diabetic mice and shown that combined medications can promote bone formation. We also analyzed the biomechanics of the tibia and found that combination drugs significantly improved maximum 
force. Stiffness, and energy absorption but the use of metformin alone also had no significant effect on the maximum force (Figure 3, Figure 6A-6F).

\section{The effect of metformin and alendronate on serum biomarkers and mRNA level in the tibia}

We further analyzed the results of serological markers and found that diabetic mice significantly reduced OCN and GLP-1 levels, but significantly increased TRAP 5b and CTX-1 levels. Combined medication can significantly reverse the process. In addition, the use of alendronate alone can significantly reduce TRAP $5 \mathrm{~b}$ levels and increase GLP-1 and the use of metformin alone can significantly increase GLP-1 and OCN levels (Figure 6G-6J).
We firstly analyzed the expression of bone metabolismrelated genes in the tibia. Diabetic mice decrease significantly in ALP, OCN, Runx2, Col-1, BMP-2, OPG, AMPK, Gfi1, and OPN and decreased significantly in Beclin-1 than the control group (Figure 7A). Besides, the use of Metformin alone can only increase significantly in ALP and the use of alendronate alone can increase significantly in OCN, AMPK, Gfil mRNA level than the control group. Secondly, we further analyzed the level of mRNA related to glucose metabolism in the tibia and found that the combined use of metformin and alendronate can significantly increase the levels of GPR43 and GPR41, GCG, and PC1/3 than diabetic mice. The use of metformin alone can also increase significantly in GPR43 and GPR41 and PC1/3 than in diabetic mice (Figure 7B).

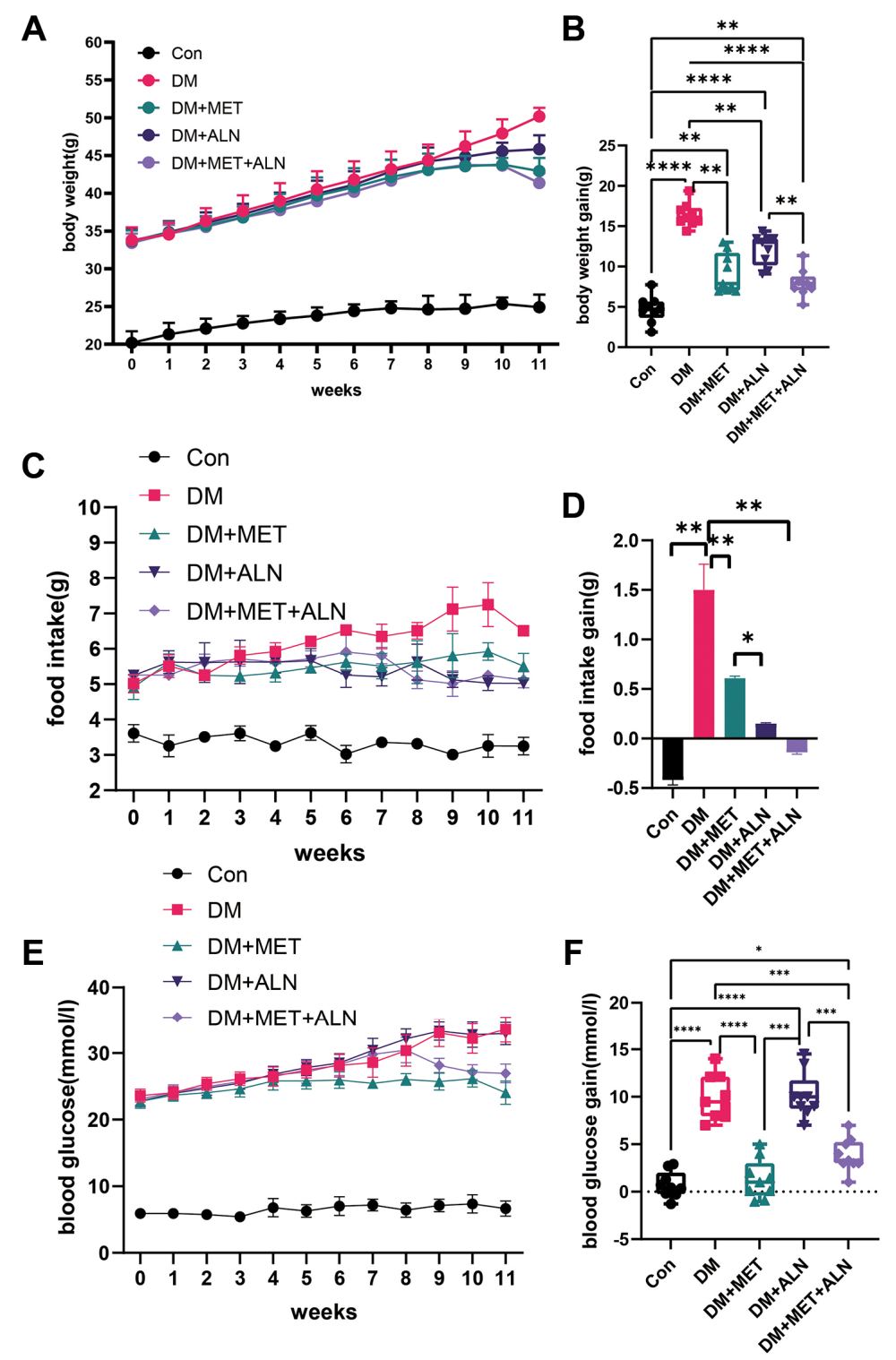

Figure 1. Effect of body weight, food intake and blood glucose in metformin and alendronate in diabetes mice. (A, B) Change of body weight in four group. (C, D) Change of food intake. (E, F) Change of blood glucose. 

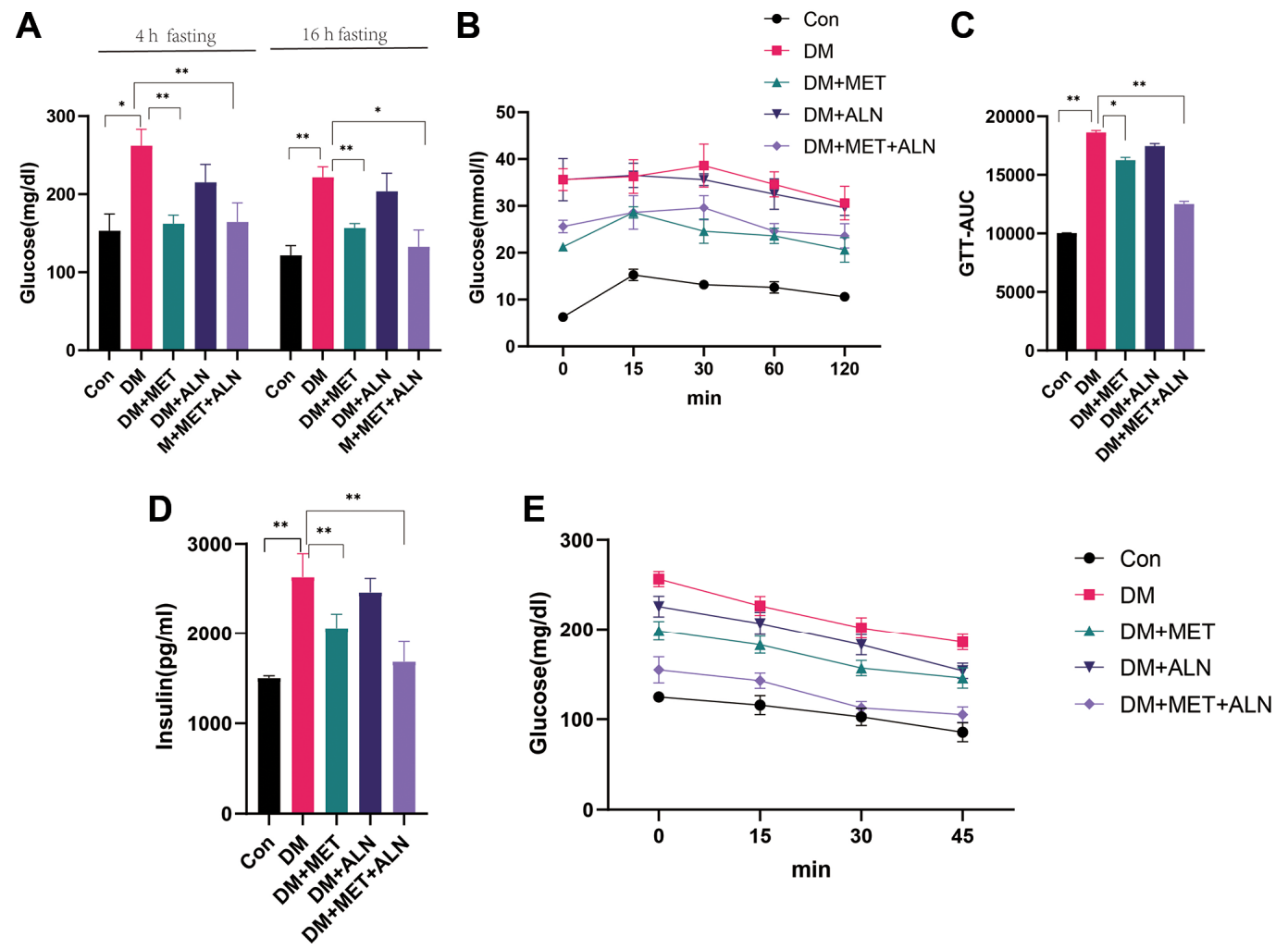

Figure 2. Effect of glucose metabolism in metformin and alendronate in diabetes mice. (A) serum glucose after 4 hour and 16 hours fasting. (B, C). GTT test. (D, E) Serum insulin and Insulin sensitivity.
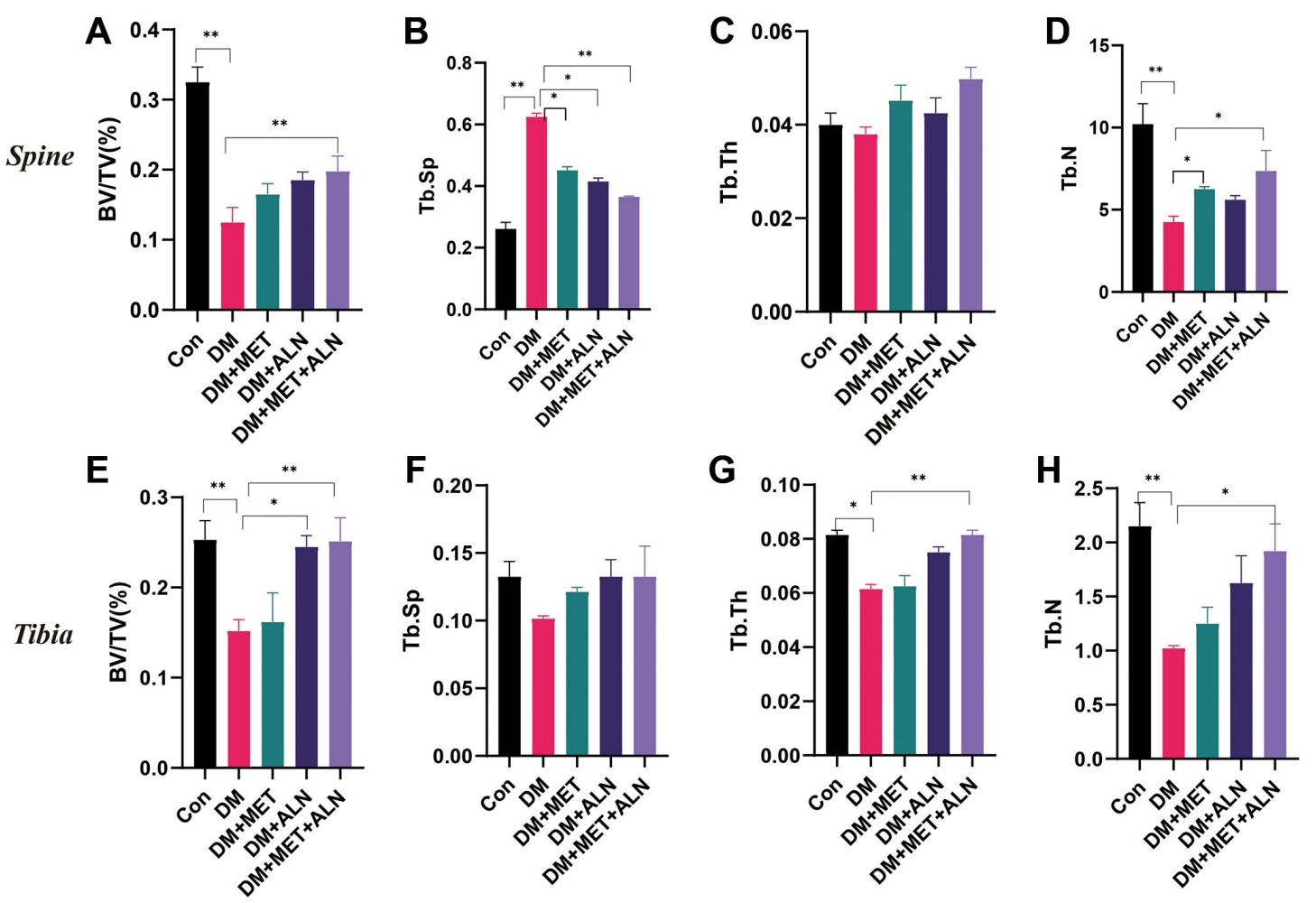

Figure 3. The effect of metformin and alendronate on bone microstructure. (A) BV/TV in spine. (B) Tb.Sp in spine. (C) Tb.Th in spine. (D) Tb.N in spine. (E) BV/TV in tibia. (F) Tb.Sp in tibia. (G) Tb.Th in tibia. (H) Tb.N in tibia. 

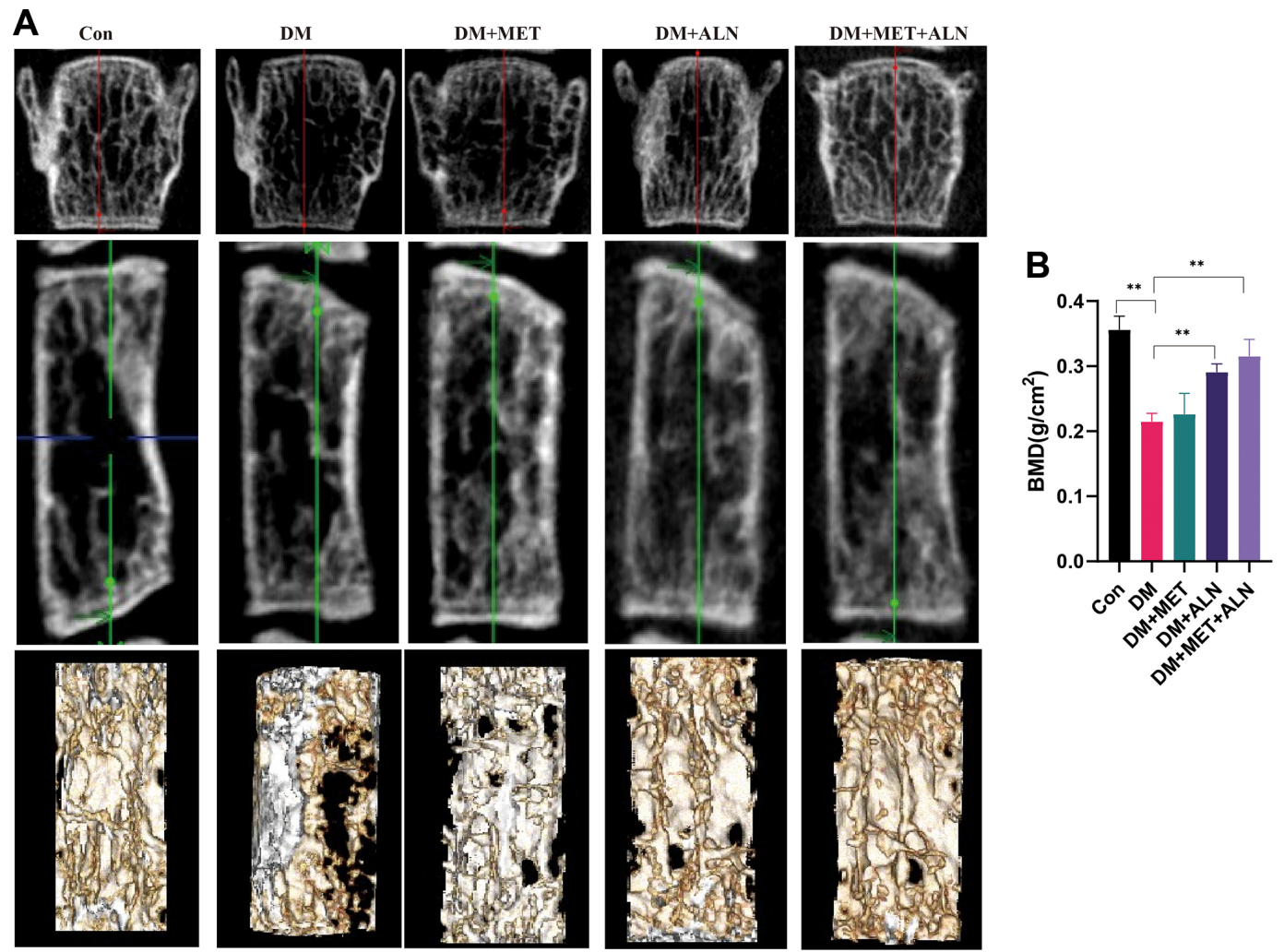

Figure 4. The effect of metformin and alendronate on bone microstructure in lumbar vertebra. (A) 3D image of Micro-CT. (B) BMD of spine.
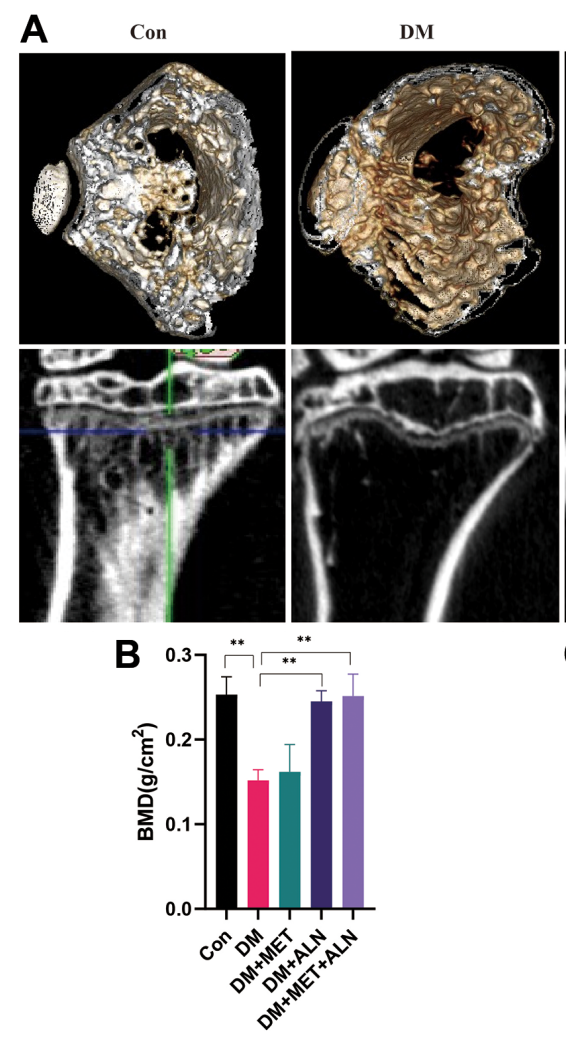

DM+MET

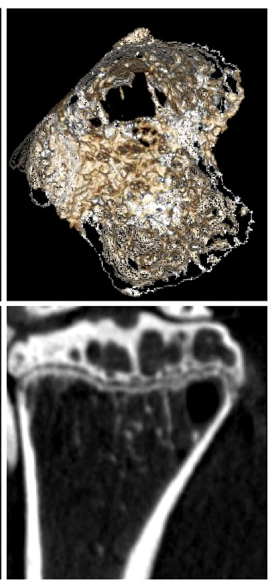

C ${ }^{250}$

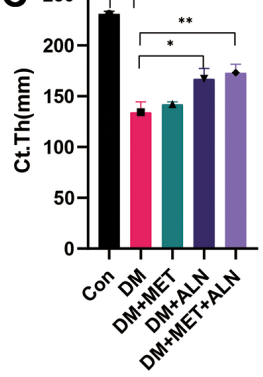

DM+ALN
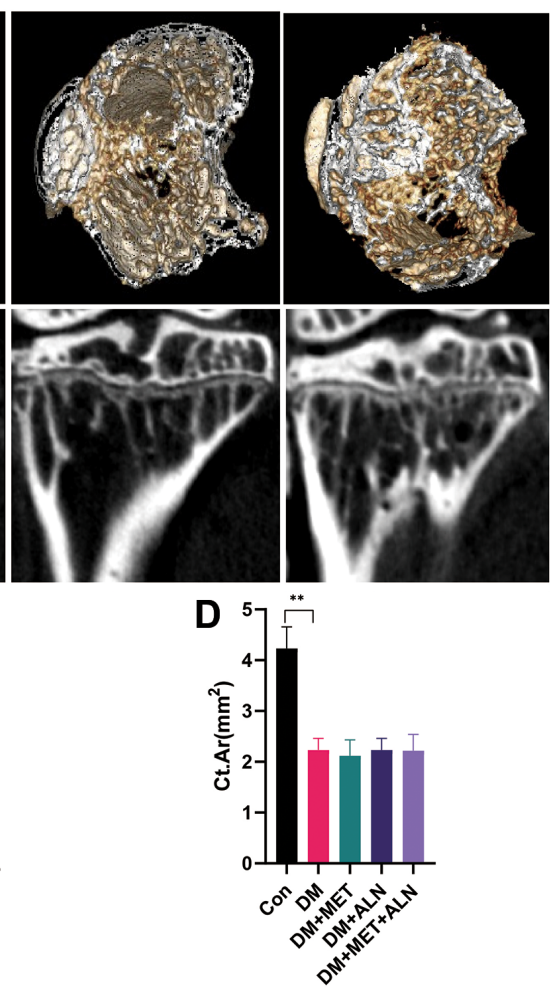

Figure 5. The effect of metformin and alendronate on bone microstructure in tibia. (A) 3D image of Micro-CT in tibia. (B) BMD of tibia. (C) Ct.Th in tibia. (D) Ct.Ar in tibia. 


\section{DISCUSSION}

In our research, the study found that the combined use of alendronate and metformin can substantially improve bone loss and glucose metabolism disorders than the diabetes group. However, the hypoglycemic effect or anti-osteoporosis effect of combining the use of alendronate and metformin is not obvious compared with the use of metformin alone or alendronate alone. It means that they appear to act no obvious synergistically between alendronate and metformin.

Osteoporosis is often accompanied by diabetes [25] and bone remodeling is compromised in both type 1 and 2 diabetes $[26,27]$. Both body weight and food intake are significantly affected by diabetes and medication. Diabetes will enhance the weight of the patient and antidiabetic treatment can improve the weight change of the patient [28-30]. This is also compatible with our research results. At the same time, alendronate can also substantially improve weight gain $[31,32]$. The improvement in body weight and food intake may better reflect the results of the improvement in bone metabolism and glucose metabolism [33-36].

The treatment of diabetes with anti-osteoporosis drugs has drawn attention $[37,38]$. In our studies, we found that the use of alendronate alone can decrease significantly in 4- and 16-hour fasting glucose and increased GLP-1 level but has not significantly decreased glucose level and insulin sensitivity in diabetic mice. It is In accordance with the present results, previous studies (e.g. Konstantinos et al.) have demonstrated that alendronate was associated with a significant 50\% reduction in the risk of incident T2DM [39]. Yang et al. also found that antiresorptive therapy was not a risk factor for diabetes [40]. Alendronate also play important role in improving fasting plasma glucose and insulin sensitivity and decreases insulin resistance in prediabetic osteopenic postmenopausal women [17]. However, in our animal experiments, we found that the use of alendronate alone has a weaker effect on glucose metabolism than the use of metformin which can improve blood glucose and insulin sensitivity.

At the same time, we have also observed that the use of metformin alone can improve the bone microstructure of the spine than the diabetes group. Consistent with the literature, this research found that participants who reported that metformin use is involved in a lower risk of osteoporosis in adult women independent of type 2 diabetes mellitus and obesity $[11,41]$. This also accords with our earlier observations, which showed that the metformin decreased bone turnover marker and
A

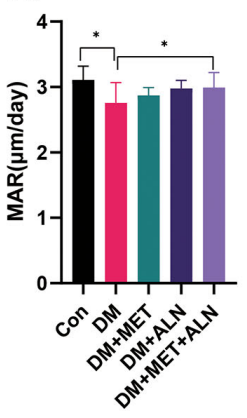

B
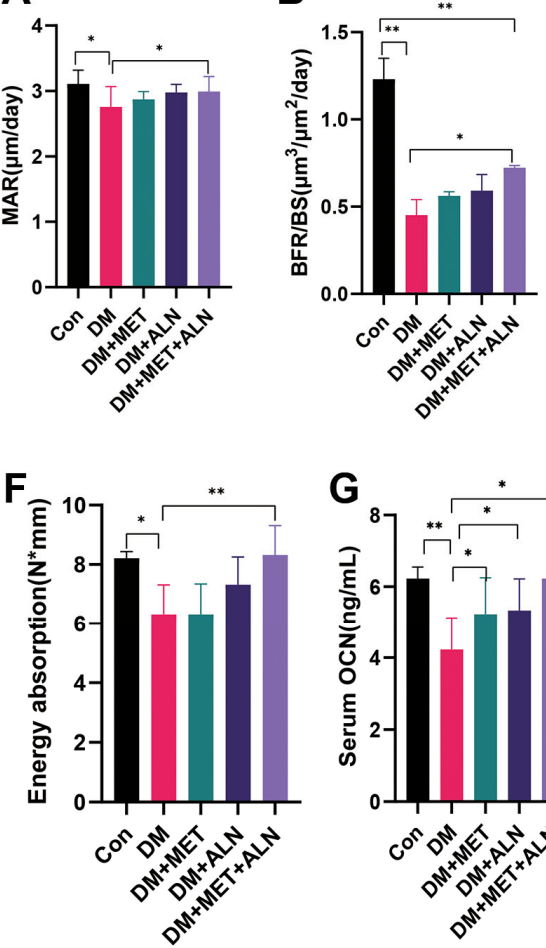

C

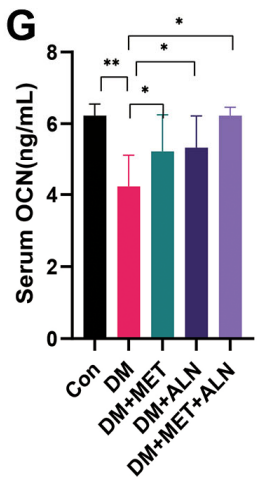

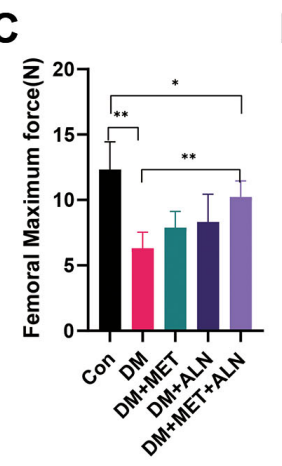

H

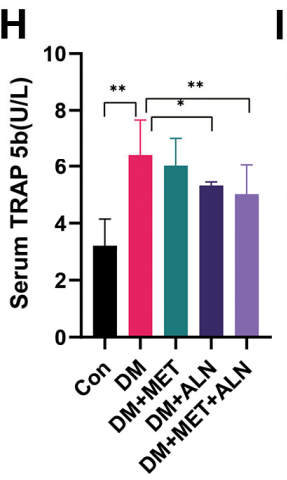

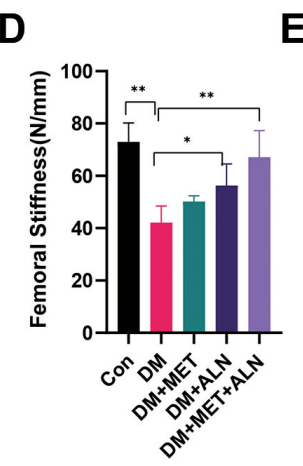
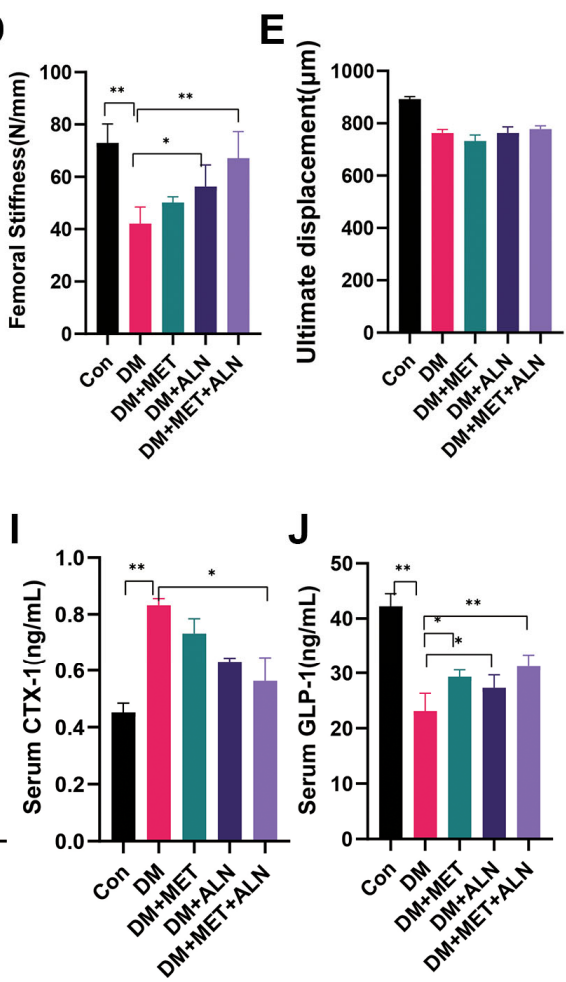

J

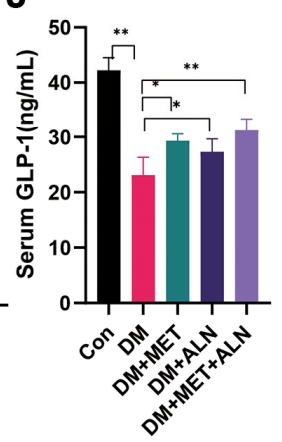

Figure 6. The effect of metformin and alendronate on serum biomarker, pathology and biomechanics. (A) mineral apposition rate (MAR). (B) bone formation rate per bone surface (BFR/BS). (C) maximum load. (D) stiffness. (E) ultimate displacement. (F) energy absorption. (G) serum OCN. (H) Serum TRAP 5b. (I) Serum CTX-1. (J) Serum GLP-1. 
influence bone formation in clinical studies [42, 43]. However, we have also noticed that the effect of metformin on bone metabolism is significantly weaker than the use of alendronate, so the use of metformin alone in the treatment of diabetic osteoporosis may require further verification. In addition, contrary to expectations, this study did not find a significant difference between the anti-osteoporosis effect of using the alendronate alone or the anti-diabetes effect of use in the alendronate and combination medication. These results further support the idea that the synergy between metformin and alendronate may be poor. However, the levels observed in this investigation are far below those observed by Lyudmila et al. It is suggested that metformin combined with alendronate significantly reduced the degree of cartilage degeneration and show the synergy in osteoarthritis. In addition, metformin can reverse some of the complications caused by alendronate, such as stomach damage [44]. A probable explanation for these results may be the lack of adequate observation time. Therefore, in our future research, we will further increase the observation time to determine whether the combined use of metformin and alendronate has a synergistic effect.
Metformin increased ALP and OCN secretion, enhanced BMP-2 expression, improved bone mineral density (BMD) [45]. In our study, it was found that metformin can improve the secretion of $\mathrm{OCN}$, but not significant improvements in osteoclast-related biological markers (for example, CTX-1 and TRAP $5 b$ ), which may indicate that metformin may play important role in the process of osteoblast [46]. Metformin can also improve the progression of diabetes through the AMPK regulation and affect the expression of BMP-2 levels, and it can also improve bone metabolism [47, 48]. AMPK-Gfil-OPN axis also play important role in bone and glucose metabolism [49]. Mai et al. found that metformin stimulates OPN and reduces RANKL expression in osteoblasts and ovariectomized rats [50-52]. OPN mediated AMPK regulation of osteogenesis and inhibited adipogenesis [49]. Besides, metformin also can inhibit the gene level of Runx2 which is associated with osteoblast differentiation markers such as OCN [53].

The effect and related mechanism of bisphosphonate on osteoporosis treatment has been widely studied [54-57]. Alendronate has a certain effect on the development of

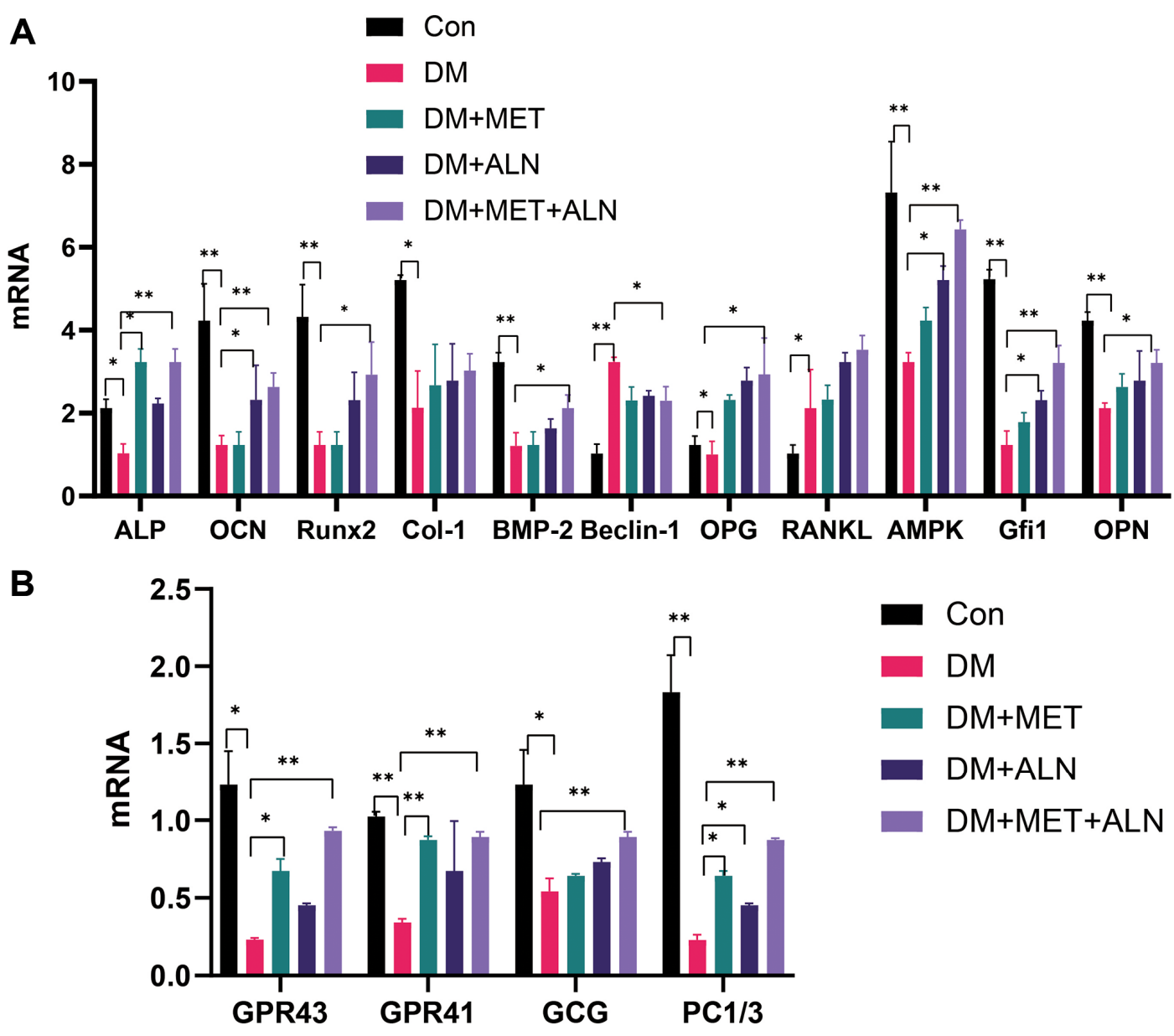

Figure 7. The relative mRNA level of tibia. (A) bone metabolism relative mRNA level. (B) glucose metabolism relative mRNA level. 
diabetes $[58,59]$. Ikeda et al. found that alendronate that produces a reduction in urinary NTx and inhibition of decrease in BMD may have a clinical significance to reduce the risk of bone fracture in postmenopausal type 2 diabetic women [60]. In this study, we found that alendronate can increase the secretion of GPL-1 and proconvertase $1 / 3(\mathrm{PC} 1 / 3)$ activity which may improve glucose metabolism [61, 62].

In our study, it was further verified that combination applications had significant improvements in diabetic osteoporosis, but the use of metformin or bisphosphonates alone did not improve osteoporosis or diabetes significantly, which also indicated that single medication in diabetic osteoporosis treatment may not be effective and further study in the clinical practical application of combination drugs.

\section{CONCLUSIONS}

In conclusion, the present study demonstrated that combining metformin and alendronate prevent the emergence of diabetes and diabetic-relative bone loss by up-regulating AMPK gene expression and secreting GLP-1, stimulating bone formation and suppressing bone resorption than diabetes group. But they appear to act no obvious synergistically between alendronate and metformin in a shorter observation period. Future studies on the current topic are therefore recommended to focus on the effect of combining the use of alendronate and metformin in diabetes and diabetic-relative bone loss.

\section{AUTHOR CONTRIBUTIONS}

Conception, design and performed experiments mentioned: QYZ, ZQG, FSL, YJX. Acquisition, analysis, and interpretation of the data: $\mathrm{GH}, \mathrm{HC}, \mathrm{XJ}$, KT, SFL. Drafting and writing: QYZ, YJX. Final approval of the article: QYZ, ZQG, GH, HC, XJ, ZYG.

\section{ACKNOWLEDGMENTS}

We would like to thank all participants and our hospital.

\section{CONFLICTS OF INTEREST}

The authors declare no conflicts of interest related to this study.

\section{FUNDING}

This work was partly supported by the Clinical Chinese Medicine Plateau Discipline Construction Project of Shanghai Pudong New Area Health Committee [grant number PDZY-2018-0604].

\section{REFERENCES}

1. Zheng $\mathrm{Y}$, Ley $\mathrm{SH}, \mathrm{Hu}$ FB. Global aetiology and epidemiology of type 2 diabetes mellitus and its complications. Nat Rev Endocrinol. 2018; 14:88-98. https://doi.org/10.1038/nrendo.2017.151 PMID:29219149

2. American Diabetes Association. 2. Classification and Diagnosis of Diabetes: Standards of Medical Care in Diabetes-2018. Diabetes Care. 2018 (Suppl 1); 41:S13-27. https://doi.org/10.2337/dc18-S002 PMID:29222373

3. Johnston CB, Dagar M. Osteoporosis in Older Adults. Med Clin North Am. 2020; 104:873-84. https://doi.org/10.1016/i.mcna.2020.06.004 PMID:32773051

4. Black DM, Rosen CJ. Clinical Practice. Postmenopausal Osteoporosis. N Engl J Med. 2016; 374:254-62. https://doi.org/10.1056/NEJMcp1513724 PMID:26789873

5. Kurra S, Fink DA, Siris ES. Osteoporosis-associated fracture and diabetes. Endocrinol Metab Clin North Am. 2014; 43:233-43.

https://doi.org/10.1016/i.ecl.2013.09.004 PMID:24582100

6. Walsh JS, Vilaca T. Obesity, Type 2 Diabetes and Bone in Adults. Calcif Tissue Int. 2017; 100:528-35. https://doi.org/10.1007/s00223-016-0229-0 PMID:28280846

7. Paschou SA, Dede AD, Anagnostis PG, Vryonidou A, Morganstein D, Goulis DG. Type 2 Diabetes and Osteoporosis: A Guide to Optimal Management. J Clin Endocrinol Metab. 2017; 102:3621-34. https://doi.org/10.1210/jc.2017-00042 PMID:28938433

8. Napoli N, Chandran M, Pierroz DD, Abrahamsen B, Schwartz AV, Ferrari SL, and IOF Bone and Diabetes Working Group. Mechanisms of diabetes mellitusinduced bone fragility. Nat Rev Endocrinol. 2017; 13:208-19.

https://doi.org/10.1038/nrendo.2016.153 PMID:27658727

9. Eller-Vainicher C, Cairoli E, Grassi G, Grassi F, Catalano A, Merlotti D, Falchetti A, Gaudio A, Chiodini I, Gennari L. Pathophysiology and Management of Type 2 Diabetes Mellitus Bone Fragility. J Diabetes Res. 2020; 2020:7608964. https://doi.org/10.1155/2020/7608964 PMID: $\underline{2566682}$

10. Dziubak A, Wójcicka G, Wojtak A, Bełtowski J. Metabolic Effects of Metformin in the Failing Heart. Int J Mol Sci. 2018; 19:2869. 
https://doi.org/10.3390/ijms19102869

PMID: $\underline{30248910}$

11. Bahrambeigi S, Yousefi B, Rahimi M, Shafiei-Irannejad V. Metformin; an old antidiabetic drug with new potentials in bone disorders. Biomed Pharmacother. 2019; 109:1593-601.

https://doi.org/10.1016/j.biopha.2018.11.032 PMID:30551413

12. Zhao J, Li Y, Zhang H, Shi D, Li Q, Meng Y, Zuo L. Preventative effects of metformin on glucocorticoidinduced osteoporosis in rats. J Bone Miner Metab. 2019; 37:805-14. https://doi.org/10.1007/s00774-019-00989-y PMID:30706148

13. Gürler EB, Çilingir-Kaya ÖT, Peker Eyüboglu I, Ercan F, Akkiprik M, Reiter RJ, Yegen BÇ. Melatonin supports alendronate in preserving bone matrix and prevents gastric inflammation in ovariectomized rats. Cell Biochem Funct. 2019; 37:102-12.

https://doi.org/10.1002/cbf.3379

PMID:30815905

14. Fan KJ, Wu J, Wang QS, Xu BX, Zhao FT, Wang TY. Metformin inhibits inflammation and bone destruction in collagen-induced arthritis in rats. Ann Transl Med. 2020; 8:1565.

https://doi.org/10.21037/atm-20-3042

PMID: 33437764

15. Jiating L, Buyun J, Yinchang Z. Role of Metformin on Osteoblast Differentiation in Type 2 Diabetes. Biomed Res Int. 2019; 2019:9203934.

https://doi.org/10.1155/2019/9203934

PMID:31886264

16. Malta FS, Garcia RP, Azarias JS, Ribeiro GKD, Miranda TS, Shibli JA, Bastos MF. Impact of hyperglycemia and treatment with metformin on ligature-induced bone loss, bone repair and expression of bone metabolism transcription factors. PLoS One. 2020; 15:e0237660. https://doi.org/10.1371/journal.pone.0237660 PMID:32841254

17. Karimi Fard M, Aminorroaya A, Kachuei A, Salamat MR, Hadi Alijanvand M, Aminorroaya Yamini S, Karimifar M, Feizi A, Amini M. Alendronate improves fasting plasma glucose and insulin sensitivity, and decreases insulin resistance in prediabetic osteopenic postmenopausal women: A randomized triple-blind clinical trial. J Diabetes Investig. 2019; 10:731-7.

https://doi.org/10.1111/idi.12944 PMID: $\underline{30267620}$

18. Anagnostis $P$, Paschou SA, Gkekas NN, Artzouchaltzi AM, Christou K, Stogiannou D, Vryonidou A, Potoupnis M, Goulis DG. Efficacy of anti-osteoporotic medications in patients with type 1 and 2 diabetes mellitus: a systematic review. Endocrine. 2018; 60:373-83.

https://doi.org/10.1007/s12020-018-1548-x

PMID:29411304

19. Zhang W, Xu JH, Yu T, Chen QK. Effects of berberine and metformin on intestinal inflammation and gut microbiome composition in $\mathrm{db} / \mathrm{db}$ mice. Biomed Pharmacother. 2019; 118:109131.

https://doi.org/10.1016/i.biopha.2019.109131 PMID:31545226

20. Mao Z, Zhu Y, Hao W, Chu C, Su H. MicroRNA-155 inhibition up-regulates LEPR to inhibit osteoclast activation and bone resorption via activation of AMPK in alendronate-treated osteoporotic mice. IUBMB Life. 2019; 71:1916-28.

https://doi.org/10.1002/iub.2131

PMID:31317664

21. Zarrinpar A, Chaix A, Xu ZZ, Chang MW, Marotz CA, Saghatelian A, Knight R, Panda S. Antibiotic-induced microbiome depletion alters metabolic homeostasis by affecting gut signaling and colonic metabolism. Nat Commun. 2018; 9:2872. https://doi.org/10.1038/s41467-018-05336-9 PMID:30030441

22. Zhang $Y$, Li XL, Sha NN, Shu B, Zhao YJ, Wang XL, Xiao $\mathrm{HH}$, Shi Q, Wong MS, Wang YJ. Differential response of bone and kidney to ACEI in db/db mice: A potential effect of captopril on accelerating bone loss. Bone. 2017; 97:222-32. https://doi.org/10.1016/j.bone.2017.01.029 PMID:28130181

23. Zhou X, Guan Z, Jin X, Zhao J, Chen G, Ding J, Ren Y, Zhai X, Zhou Q, Guan Z. Reversal of alopecia areata, osteoporosis follow treatment with activation of Tgr5 in mice. Biosci Rep. 2021; 41:BSR20210609.

https://doi.org/10.1042/BSR20210609

PMID:34196345

24. Li J, Zeng Z, Zhao $Y$, Jing D, Tang C, Ding $Y$, Feng $X$. Effects of low-intensity pulsed electromagnetic fields on bone microarchitecture, mechanical strength and bone turnover in type 2 diabetic db/db mice. Sci Rep. 2017; 7:10834.

https://doi.org/10.1038/s41598-017-11090-7 PMID:28883516

25. Lecka-Czernik B. Diabetes, bone and glucoselowering agents: basic biology. Diabetologia. 2017; 60:1163-9.

https://doi.org/10.1007/s00125-017-4269-4 PMID:28434032

26. Khosla S, Hofbauer LC. Osteoporosis treatment: recent developments and ongoing challenges. Lancet Diabetes Endocrinol. 2017; 5:898-907. 
https://doi.org/10.1016/S2213-8587(17)30188-2 PMID:28689769

27. Ferrari SL, Abrahamsen B, Napoli N, Akesson K, Chandran M, Eastell R, El-Hajj Fuleihan G, Josse R, Kendler DL, Kraenzlin M, Suzuki A, Pierroz DD, Schwartz AV, Leslie WD, and Bone and Diabetes Working Group of IOF. Diagnosis and management of bone fragility in diabetes: an emerging challenge. Osteoporos Int. 2018; 29:2585-96. https://doi.org/10.1007/s00198-018-4650-2 PMID: 30066131

28. Mavian AA, Miller S, Henry RR. Managing type 2 diabetes: balancing HbA1c and body weight. Postgrad Med. 2010; 122:106-17.

https://doi.org/10.3810/pgm.2010.05.2148 PMID:20463420

29. Lau DC, Teoh H. Impact of Current and Emerging Glucose-Lowering Drugs on Body Weight in Type 2 Diabetes. Can J Diabetes. 2015 (Suppl 5); 39:S148-54. https://doi.org/10.1016/i.jcjd.2015.09.090 PMID:26654858

30. Fromenty B, Vadrot N, Massart J, Turlin B, Barri-Ova $N$, Lettéron $P$, Fautrel $A$, Robin MA. Chronic ethanol consumption lessens the gain of body weight, liver triglycerides, and diabetes in obese ob/ob mice. J Pharmacol Exp Ther. 2009; 331:23-34.

https://doi.org/10.1124/ipet.109.155168 PMID:19587315

31. Reid IR, Horne AM, Mihov B, Stewart A, Bastin S, Gamble GD. Zoledronate Slows Weight Loss and Maintains Fat Mass in Osteopenic Older Women: Secondary Analysis of a Randomized Controlled Trial. Calcif Tissue Int. 2020; 106:386-91. https://doi.org/10.1007/s00223-019-00653-7 PMID:31897528

32. Kaji H, Hisa I, Inoue $Y$, Naito J, Sugimoto T, Kasuga M. Analysis of factors affecting increase in bone mineral density at lumbar spine by bisphosphonate treatment in postmenopausal osteoporosis. J Bone Miner Metab. 2009; 27:76-82.

https://doi.org/10.1007/s00774-008-0005-y PMID:19018454

33. Izzi-Engbeaya C, Ma Y, Buckley NW, Ratnasabapathy R, Richardson E, Counsell JR, Fernandes-Freitas I, Norton M, Farooq G, Mirza Z, Cai M, Cheetham S, Seckl J, et al. Effects of corticosterone within the hypothalamic arcuate nucleus on food intake and body weight in male rats. Mol Metab. 2020; 36:100972. https://doi.org/10.1016/j.molmet.2020.02.015 PMID: $\underline{32229097}$

34. Gibbons C, Blundell J, Tetens Hoff S, Dahl K, Bauer R, Baekdal T. Effects of oral semaglutide on energy intake, food preference, appetite, control of eating and body weight in subjects with type 2 diabetes. Diabetes Obes Metab. 2021; 23:581-8.

https://doi.org/10.1111/dom.14255

PMID:33184979

35. Beccuti G, Monagheddu C, Evangelista A, Ciccone G, Broglio F, Soldati L, Bo S. Timing of food intake: Sounding the alarm about metabolic impairments? A systematic review. Pharmacol Res. 2017; 125:132-41. https://doi.org/10.1016/j.phrs.2017.09.005 PMID:28928073

36. Argyrakopoulou G, Simati S, Dimitriadis G, Kokkinos A. How Important Is Eating Rate in the Physiological Response to Food Intake, Control of Body Weight, and Glycemia? Nutrients. 2020; 12:1734. https://doi.org/10.3390/nu12061734 PMID:32532002

37. Mohsin S, Baniyas MM, AlDarmaki RS, Tekes K, Kalász $\mathrm{H}$, Adeghate EA. An update on therapies for the treatment of diabetes-induced osteoporosis. Expert Opin Biol Ther. 2019; 19:937-48. https://doi.org/10.1080/14712598.2019.1618266 PMID:31079501

38. Panagiotakou A, Yavropoulou M, Nasiri-Ansari N, Makras P, Basdra EK, Papavassiliou AG, Kassi EN. Extraskeletal effects of bisphosphonates. Metabolism. 2020; 110:154264.

https://doi.org/10.1016/j.metabol.2020.154264 PMID: $\underline{32445641}$

39. Toulis KA, Nirantharakumar K, Ryan R, Marshall T, Hemming K. Bisphosphonates and glucose homeostasis: a population-based, retrospective cohort study. J Clin Endocrinol Metab. 2015; 100:1933-40. https://doi.org/10.1210/jc.2014-3481 PMID:25695881

40. Yang S, Leslie WD, Morin SN, Majumdar SR, Lix LM. Antiresorptive therapy and newly diagnosed diabetes in women: a historical cohort study. Diabetes Obes Metab. 2016; 18:875-81.

https://doi.org/10.1111/dom.12678

PMID:27097832

41. Blümel JE, Arteaga $E$, Aedo S, Arriola-Montenegro J, López M, Martino M, Miranda C, Miranda O, Mostajo $D$, Ñañez $M$, Ojeda $E$, Pilnik $S$, Rojas J, et al. Metformin use is associated with a lower risk of osteoporosis in adult women independent of type 2 diabetes mellitus and obesity. REDLINC IX study. Gynecol Endocrinol. 2020; 36:421-5. https://doi.org/10.1080/09513590.2020.1718092 PMID: $\underline{31994945}$

42. Lingaiah S, Morin-Papunen L, Risteli J, Tapanainen JS. Metformin decreases bone turnover markers in 
polycystic ovary syndrome: a post hoc study. Fertil Steril. 2019; 112:362-70.

https://doi.org/10.1016/j.fertnstert.2019.04.013

PMID:31227287

43. van Lierop $A H$, Hamdy NA, van der Meer RW, Jonker JT, Lamb HJ, Rijzewijk LJ, Diamant M, Romijn JA, Smit JW, Papapoulos SE. Distinct effects of pioglitazone and metformin on circulating sclerostin and biochemical markers of bone turnover in men with type 2 diabetes mellitus. Eur J Endocrinol. 2012; 166:711-6.

https://doi.org/10.1530/EJE-11-1061

PMID:22267280

44. Nolêto IRS, lles B, Alencar MS, Lopes ALF, Oliveira AP, Pacheco G, Sousa FBM, Araújo AR, Alves EHP, Vasconcelos DFP, Leal LKA, Araújo AJ, Filho JDB, Medeiros JVR. Alendronate-induced gastric damage in normoglycemic and hyperglycemic rats is reversed by metformin. Eur J Pharmacol. 2019; 856:172410.

https://doi.org/10.1016/j.ejphar.2019.172410 PMID:31132357

45. Zheng L, Shen X, Ye J, Xie Y, Yan S. Metformin alleviates hyperglycemia-induced apoptosis and differentiation suppression in osteoblasts through inhibiting the TLR4 signaling pathway. Life Sci. 2019; 216:29-38.

https://doi.org/10.1016/i.lfs.2018.11.008 PMID:30414431

46. Park SH, Kang MA, Moon YJ, Jang KY, Kim JR. Metformin coordinates osteoblast/osteoclast differentiation associated with ischemic osteonecrosis. Aging (Albany NY). 2020; 12:4727-41. https://doi.org/10.18632/aging.102796 PMID:32045366

47. McCarthy AD, Cortizo AM, Sedlinsky C. Metformin revisited: Does this regulator of AMP-activated protein kinase secondarily affect bone metabolism and prevent diabetic osteopathy. World J Diabetes. 2016; 7:122-33.

https://doi.org/10.4239/wjd.v7.i6.122 PMID:27022443

48. Kanazawa I, Yamaguchi T, Yano S, Yamauchi M, Sugimoto T. Metformin enhances the differentiation and mineralization of osteoblastic MC3T3-E1 cells via AMP kinase activation as well as eNOS and BMP-2 expression. Biochem Biophys Res Commun. 2008; 375:414-9.

https://doi.org/10.1016/i.bbrc.2008.08.034 PMID: 18721796

49. Wang YG, Qu XH, Yang $Y$, Han XG, Wang L, Qiao $H$, Fan QM, Tang TT, Dai KR. AMPK promotes osteogenesis and inhibits adipogenesis through AMPK-Gfi1-OPN axis. Cell Signal. 2016; 28:1270-82. https://doi.org/10.1016/j.cellsig.2016.06.004 PMID:27283242

50. Shin HS, Sun HJ, Whang YM, Park YJ, Park DJ, Cho SW. Metformin Reduces Thyroid Cancer Tumor Growth in the Metastatic Niche of Bone by Inhibiting Osteoblastic RANKL Productions. Thyroid. 2021; 31:760-71. https://doi.org/10.1089/thy.2019.0851 PMID:32791889

51. Mai QG, Zhang ZM, Xu S, Lu M, Zhou RP, Zhao L, Jia $\mathrm{CH}$, Wen $\mathrm{ZH}$, Jin DD, Bai XC. Metformin stimulates osteoprotegerin and reduces RANKL expression in osteoblasts and ovariectomized rats. J Cell Biochem. 2011; 112:2902-9. https://doi.org/10.1002/jcb.23206 PMID:21618594

52. Araújo AA, Pereira ASB, Medeiros CAC, Brito GAC, Leitão RFC, Araújo LS, Guedes PMM, Hiyari S, Pirih $F Q$, Araújo Júnior RF. Effects of metformin on inflammation, oxidative stress, and bone loss in a rat model of periodontitis. PLoS One. 2017; 12:e0183506. https://doi.org/10.1371/journal.pone.0183506 PMID:28847008

53. Kasai T, Bandow K, Suzuki H, Chiba N, Kakimoto K, Ohnishi T, Kawamoto S, Nagaoka E, Matsuguchi T. Osteoblast differentiation is functionally associated with decreased AMP kinase activity. J Cell Physiol. 2009; 221:740-9. https://doi.org/10.1002/icp.21917 PMID:19725053

54. Sharpe M, Noble S, Spencer CM. Alendronate: an update of its use in osteoporosis. Drugs. 2001; 61:999-1039.

https://doi.org/10.2165/00003495-200161070-00010 PMID: 11434454

55. Porras AG, Holland SD, Gertz BJ. Pharmacokinetics of alendronate. Clin Pharmacokinet. 1999; 36:315-28. https://doi.org/10.2165/00003088-199936050-00002 PMID:10384857

56. Pérez-López FR. Postmenopausal osteoporosis and alendronate. Maturitas. 2004; 48:179-92.

https://doi.org/10.1016/j.maturitas.2003.12.006 PMID: 15207883

57. Leder BZ, Mitlak B, Hu MY, Hattersley G, Bockman RS. Effect of Abaloparatide vs Alendronate on Fracture Risk Reduction in Postmenopausal Women With Osteoporosis. J Clin Endocrinol Metab. 2020; 105:938-43.

https://doi.org/10.1210/clinem/dgz162

PMID:31674644

58. Chuguransky SR, Cortizo AM, McCarthy AD. Alendronate Can Improve Bone Alterations in 
Experimental Diabetes by Preventing Antiosteogenic, Antichondrogenic, and Proadipocytic Effects of AGEs on Bone Marrow Progenitor Cells. Biomed Res Int. 2016; 2016:5891925.

https://doi.org/10.1155/2016/5891925

PMID:27840829

59. Berti-Couto SA, Vasconcelos AC, Iglesias JE, Figueiredo MA, Salum FG, Cherubini K. Diabetes mellitus and corticotherapy as risk factors for alendronate-related osteonecrosis of the jaws: a study in Wistar rats. Head Neck. 2014; 36:84-93.

https://doi.org/10.1002/hed.23260

PMID:23649954

60. Ikeda $\mathrm{T}$, Manabe $\mathrm{H}$, Iwata $\mathrm{K}$. Clinical significance of alendronate in postmenopausal type 2 diabetes mellitus. Diabetes Metab. 2004; 30:355-8.

https://doi.org/10.1016/s1262-3636(07)70128-3

PMID:15525879
61. Wideman RD, Gray SL, Covey SD, Webb GC, Kieffer TJ. Transplantation of PC1/3-Expressing alpha-cells improves glucose handling and cold tolerance in leptin-resistant mice. Mol Ther. 2009; 17:191-8.

https://doi.org/10.1038/mt.2008.219

PMID: 18941442

62. Sancho V, Daniele G, Lucchesi D, Lupi R, Ciccarone A, Penno G, Bianchi C, Dardano A, Miccoli R, Del Prato S. Metabolic regulation of GLP-1 and $P C 1 / 3$ in pancreatic $\alpha$-cell line. PLoS One. 2017; 12:e0187836. https://doi.org/10.1371/journal.pone.0187836 PMID:29121068 


\section{SUPPLEMENTARY MATERIALS}

\section{Supplementary Table}

Supplementary Table 1. Primer sequences used for RT-QPCR.

\begin{tabular}{lcc}
\hline & Forward primer sequences & Reverse primer sequences \\
\hline GAPDH & AACTTTGGCATTGTGGAAGG & ACACATTGGGGGTAGGAACA \\
GPR43 & CTGGCACAGTTCCTTGATCCTCAC & GGCAGCAGCAGCAACAGGAG \\
GPR41 & TGCTCATCTTCTTCGTCTGCTTCG & GTCGGCTTGGAACTTGGAGGAAG \\
GCG & ATTCATTGCTTGGCTGGTGA & CCAGAATGGTGCTCATCTCG \\
PC1/3 & ACATGGGGAGAGAATCCTGTAGGCA & CATGGCCTTTGAAGGAGTTCCTTGT \\
ALP & TGGTTACTGCTGATCATTCCCACG & AATGTAGTTCTGCTCATGGACGCC \\
COL1A1 & GCTCCTCTTAGGGGCCACT & ATTGGGGACCCTTAGGCCAT \\
OCN & AAGCAGGAGGGCAATAAGGT & TAGGCGGTCTTCAAGCCAT \\
BMP-2 & TATGGATCCACTTAAGATGG & TATTGCGGC \\
Runx-2 & TGGCCGGGACCCGCTGT & CGCTTAACGACACCCGCAGCCCTC \\
Beclin-1 & CCTTCCAGACCAGCAGCAG & TCCGTCAGCGTCAACACCA \\
AMPK & GCTGTAGCCAGCCTCTGAAA & AATGGCTCCTGTGAGTTCCTG \\
OPG & TGATGATGAGGCTGTGAA & TAGAGGCGAGG TAGAACT \\
Gfil & GAGGAGTCTGGTAGTGGTTCC & GGGCGTTTCGTTGAATATGCG \\
OPN & 5-TTCTCTCGCTGCGGAGTCT-3 & AGGCACTAGAAATGACTTGAAAGAAAA \\
RANKL & AGACACTTTCACTCCAATCGTCCC & TGGTTCATCCAGCTGACTTGACTC \\
\hline
\end{tabular}

